\title{
[ 252$]$
}

\begin{abstract}
V.
VER IV A, N D L U N G

der Alkalien in Metalle durch galvani'fche Electricitüt.

Dritte Nachricht von den Verfuchen der Herren v. JACQUiN, S CIIRIBRIS, TaHavsKy

und BKEMSER;

in cinem Schreiben des Herrn Freiherrn von Jacquin an den Prof. Gilbert in Halle.

Wien den 24 ften Februar 1808.

Bei unfern fortgefetzten Verfuchen zur Erforfcliung des weitern Eigenfchaften von Davy's metallificher Subfanz aus dem Kali, ${ }^{*}$ ) und der nähern Umftände ihrer Ablcheidung, finclen wir eine befondere Schwierigkeit in der fo grofsen Zerftörbarkeit derfetben; denn felbft in der Naphtha oder dem rectificirten Steinöhl erhält Ge fich kaum ein Paar Stunden lang in ilurem urfprünglichen $\mathrm{Zu}$ ftande. Sie läuft fogleich an der Oberfläche erft bleigrau, dann eifengrau, dann gold-und meffinggelb an, und verliert endlich den metallifchen Glanz

*) Wir werden Kürze halber diefe Subfanz in der Folge Kali-Mctall nennen, wenn man gleich aus den bisher bekannten Verfachen die Zufammenferzung des Kali aus ihr und aus Sauerfoff noch nicht für ganz erwiefen anericunen kann.
\end{abstract}

v. J. 


\section{[ 253 ]}

völlig, indem fie fich mit einer zähen, gelburaunen Materie, eine Art Naphibafeife, aberzieht, in welche fie höchftens in ein Paar Tagen gänzlich abergeht.

Da die Auffammlung der einzelnen Körner mit der metailenen Nadel *) fehr mühfam und langwierig war, fo bedienen wir uns gegenwärtig des folgenden Apparats, wodurch das Kali-Metall nicht nur in grölserer Menge, fchnelier und reiner, fondern auch von felbft abgefchieden wird. Ein kleines plattes Stäck Kali, welches an der Luft fo viel Feuchtigkeit angezogen hat, dafs es dem Zerfliefsen nahe ift, wird in einem Schälchen voll Naphtha auf eine mit dem,Hydrogenpole der Batterie verbundene Platinplatte gelegt, und von oben mit eipem metallenen Stiele, welcher mit dem Oxygenpol in Verbindung lteht, feft auf die Platinplatte niedergetrückt. Die Geftalt diefes letzten Letters ift gleicngültig, fpitzig, ftumpf, dicker oder clün: ner, fo wie auch jectes Metall dazu dienen kann. So wie die Ketie gelchloffen wird, erfolgen deutlicbe Zeicben der Zerlegung, Gasentwickelung ain Oxygenpole, welche ficb gegren die Ränder der Platinplatte hinzieht; mitunter auch Detonationen mit Dampf und Hydrogengerich. Zugieich fcheiden fich häufig kleine Metallkörner aus, die anfangs fchwimmen, bald aber an der Oberfäche oxydirt

*) Man fehe unfere enfte Nachriclit in dem vorigen Hefte, S. 132 .

$2 . J$. 


\section{[ 254 ]}

zu Boden finken. Noch mehrere folche Metallkörner, und zwar gröfsere, entftehen durch Zufammenfliefsung an den Kanten des Kali und an def. fen unterer Fläche gegen'den Rand zu, wo es auf der Platioplatte auflag. In Zeit von einer halben Stunde erhalten wir auf diefe Art ohne weiteres Zuthun mehr von dem Kalimetalle, als wir nach der eritern Methode, bei anbaltender Bemulhung, in einem halben Tage zu bereiten fähig waren. Ein folches Präparat nimmt fich unter dem Mikrofkope fehr fchün aus. Das Metall läfst fich leicht mit einer Nadel oder Pincette zu anderweitigen Verfuchen herab nehmen.

Das Kalimetall befitzt, wie fchon in meinem letzten Briefe erwähnt worcien, (S. 147,) bei der Temperatur von $+60^{\circ}$ Falır. eine Confiftenz, wie ein fefterer Quickbrei. Es lälst fich mit einer grofsen Nadel platt fletfichen und in Stücke zertiseilen, wobei es im Bruche körnig erfcheint. Selhft das unter der Naptstha fchon mellinggelb angeiaufene Metall zeigt dann in frifchen Bruche noch feine urfprüngliche Farbe und feinen Metallglanz. Man kann mehrere folche kleinere Metallkörner in ein gröfseres zufammen kiseten, um grüfsere Detonationsverfuche $u$. dgl. damit vorzunehmen. Vienn man mehrere unter Naphtía befindliche Metallkörner erwärmt, fo werden fie zwar ganz $\operatorname{la} / j$ g $g$ wie Queckfilber, vereinigen fich aber nicht, weil fie in der Naphintha nicht zu Boden friken, fondern darin nur fchweben, und bei der durch Wärme in 


\section{[ 255 ]}

derfelben hervor gebrachten Bewegung heruin getrieben und noch mehr zertheilt werden.

Die Amalgamirung des Queskflivers mit dem. Kalinetalle gelingt uns nicht fo leicht, als es nach Davy in den erften Nachrichten angegeben wird. Ein an einer Platinnadel hängendes Korn liefs fich tief in QQueckfilber tauchen, ohne von der Nadel loszugehen, und detonirte darauf im Waffer, wie fonft. Durch Zufammenkneten gelang es, einige Körner des Kalimetalles mit einem Queckfilberkügelchen zu vereinigen, welches dann in Wafler gebracht, das Kalimetall unter allinähligen Detona* tionen wieder ausfchied.

Ein unter Naphtha befindliches Stäckchen Kali wurde mit dem Oxygerpole durch Eilen verbunden; am Hydrogeopole befand fich eine Platinnadel, und zwilchen der Spitze derfelben und dem Rande des Kali ein Tropien Queckfiber. Unter den gewöhnlichen Nebenphäromenen der Gasentbindung kam un das Queckfiber und auf lemfelben, zurinahl da, wo die Platinnadel anlag, ein fchwarzes Pulver zum Vorfcheine, welches in Warfer langfaun detonirte. Am liande des Kali, wo das Queckfilber unmittelbar anlag, zeigte fich keine Wirkung.

In eine Weingeifflamme gehalten, blähen fich die Körner des Kalimetalles auf, werden weifs, und verlieren ihre Eigenfchaft, mit Walfer zu detoniren. Auf glühende Ko/hle gelegt, fcheint das nänliche zu erfolgen. 


\section{[ $\begin{array}{ll}256 & \text { ] }\end{array}$}

Körner des Kalimetalles neuerdings unter Naphtha der Wirkung der Batterie ausgefetzt, entzuinden fich und verbrennen zum Theil, wobei das ührig gebliebene Metail reiner und metallifcher glänzend wird.

Der Magnet wirkt nicht auf das Kalinetall, und magnetiGrte Leiter wirken bei Erzeugung des Metalles nur wie jede andere Metalllpitze.

Kali-Schwefelleber giebt ännlicheị Metallkörner wie reines Kali, und es zeigt fich keine Spur von Schwefelgehalt an denfelben; die ain Oxygenpol fich zeigenden Funken find aber rotll.

Wir bedienen uns gegenwärtig einer Batterie von 1300 Plattenpaaren und 70 Quadratfufs Bcrührungsfäche. Die Stärke der Batterie fcheint mehs Einflufs auf die Grölse der erzeugten Metallkürner als auf ibre folnelle Entivickelung zu haben, und kleine Platten folheinen in einem gröfsern Verialtniffe zu wirien, als grofse, bei gleicher Berührungsfäche.

$$
\text { Joleph Freiherr von Jacquin. }
$$

\section{Berichtigung $\approx$ u Seite 148 und 150 .}

Die Preisvertheilung wurie in einer offenticinen firzung des Nat. - Ind. an fitn Jan. 1 sos Uekannt gumarlut. Im Honiceurkommen keine nuchert Nackrichten ron $D$ a vy's ke-tuclien, als aus dem \$. 153 magetheilien londner Briefe vor; der Sotiz aus der al!gem. Zeie., \$. I $50 \mathrm{f}$, liegt daher kein trikel aus dem Moniseur xum Grunde. Nach Brieten aus Paris vom 3.jlien Februar haite Hers $G$ a y - Lullac aus angehatuchem Kali kleine Metuliagelchen, vamitellt eincr Situle von ion lanen

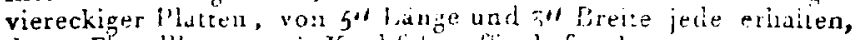
deren Flanellippen anit Kuchlitizwalior befeuchtel waron. 
Saf. II.

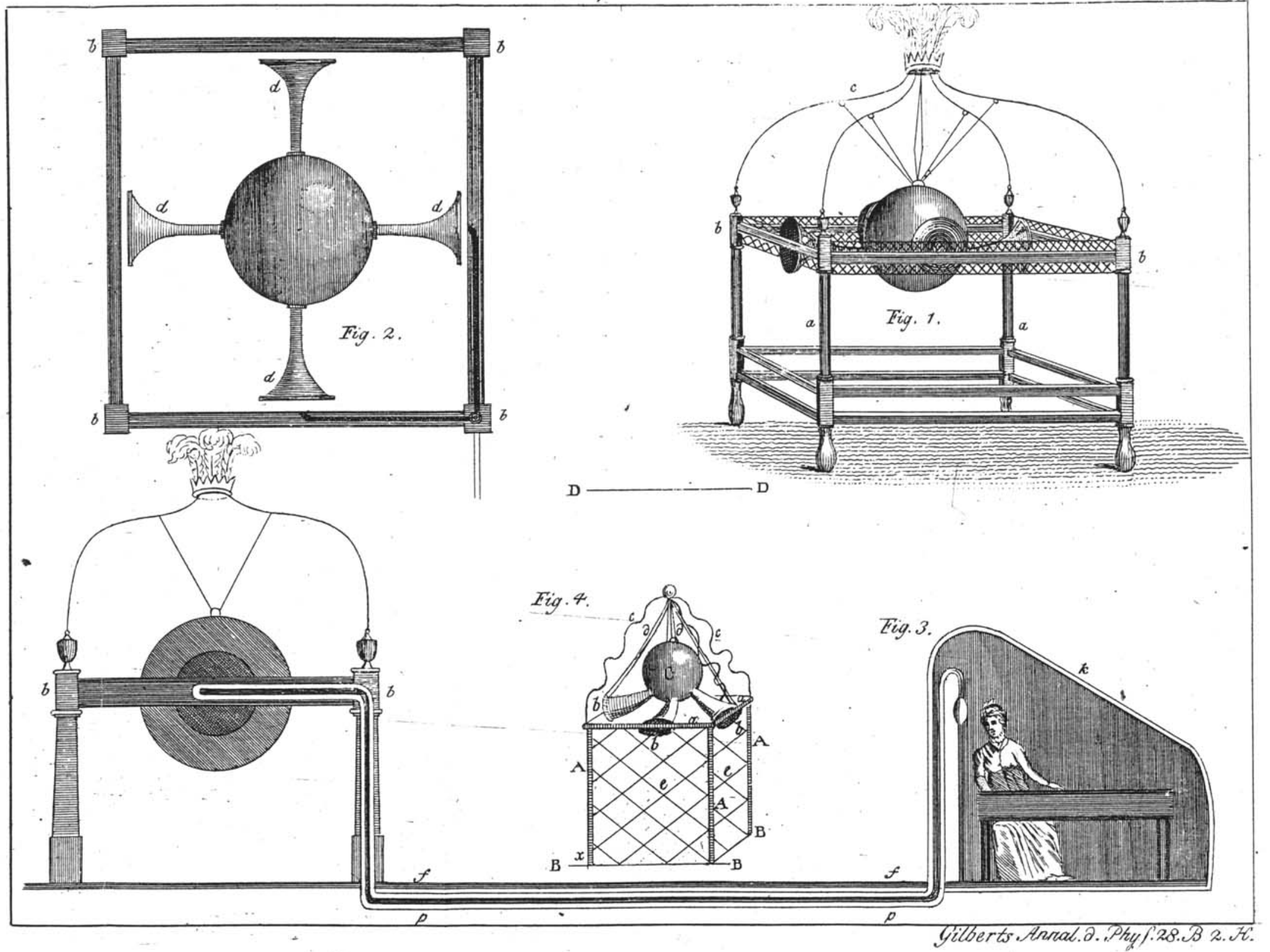

